Received: 2 March 2017

Accepted: 19 May 2017

Published online: 03 July 2017

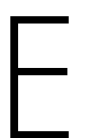

C NTF

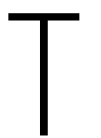

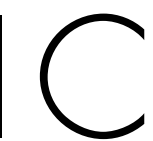

REP

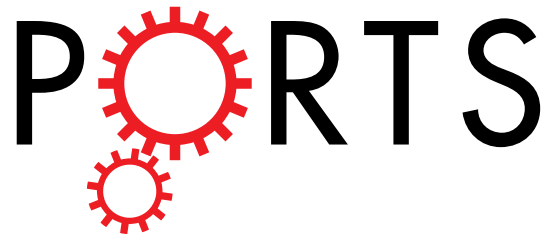

\title{
OPEN
}

\section{Triplex DNA-based Bioanalytical Platform for Highly Sensitive Homogeneous Electrochemical Detection of Melamine}

\begin{abstract}
Xiaojuan Liu, Mengmeng Song \& Feng Li
Melamine detection has attracted much attention since the discovery of the damage of melamine to human health. Herein, we have developed a sensitive homogeneous electroanalytical platform for melamine detection, which is relied on the formation of triplex molecular beacon integrated with exonuclease III (Exo III)-mediated signal amplification. The formation of triplex molecular beacon was triggered by the recognition and incorporation of melamine to the abasic (AP) site contained in the triplex stem. The stem of the triplex molecular beacon was designed to have a protruding doublestrand DNA, which can be recognized and hydrolyzed by Exo III for releasing methylene blue (MB)labeled mononucleotide. These released MB molecules exhibit high diffusivity toward indium tin oxide electrode with negative charge, thus producing a significantly increased electrochemical response. Taking advantages of the high binding affinity of the DNA triplex structure containing AP sites towards melamine and the unique features of Exo III, this sensing platform is capable for sensitive and selective melamine assay with a detection limit as low as $8.7 \mathrm{nM}$. Furthermore, this strategy shows good applicability for melamine assay in real samples. Therefore, this strategy broadens the application of triplex DNA and presents a new method for sensitive detection of melamine.
\end{abstract}

Melamine, which is a triazine heterocyclic organic compound, has been widely used in the production of plastics, coatings, flame retardants, melamine resins, and other products ${ }^{1}$. In the past years, melamine has been illegally and unethically added to food and animal feeds to increase its apparent crude protein content, because customary Kjeldahl protein analysis approach fails to distinguish the nitrogen sources of protein from that of non-protein ${ }^{2}$. However, the intake of melamine for human and animals could lead to the formation of insoluble complexes in kidney and subsequent tissue injury ${ }^{3}$. Therefore, much effort has been focused on developing reliable methods for detecting melamine in food, whereas little attention has been paid on monitoring melamine contained in the food chain, such as food crops grown by nitrogenous fertilizers, animal meat fed by melamine-mixed feeds. As those melamine-contaminated foods are easily ignored, it is of great importance to establish effective and reliable assay for monitoring melamine at the source of the food chain.

Traditional melamine detection methods include mass spectroscopy $(\mathrm{MS})^{4}$, gas chromatography/mass spectrum (GC/MS $)^{5}$, high performance liquid chromatography (HPLC) ${ }^{6}$ and so on. Although these approaches can achieve high sensitivity and selectivity, they are usually dependent on expensive instruments, time-consuming sample pretreatment, careful calibration, and skilled manpower, which greatly limit their utility in routine melamine determination. To overcome these problems, various alternative methods have been explored for detecting melamine, such as colorimetric assay ${ }^{7-10}$, fluorometric assay ${ }^{11,12}$, surface enhanced Raman scattering $(\text { SERS })^{13}$, immunoassay approaches ${ }^{14}$, electrochemical methods ${ }^{15}{ }^{16}$. Among them, electrochemical method, as a useful analytical technology, has been extensively employed because of its outstanding merits of inexpensive, fast detection, convenient operation procedures, high sensitivity, and compatibility with micro-manufacturing techniques $^{17,18}$. In particularly, recently developed homogeneous electrochemical methods open a promising way for the design of immobilization-free electrochemical biosensors ${ }^{19-21}$. In these biosensors, the recognition of analyte and subsequent reaction are performed in homogeneous solution instead of the interface between the solution phase and electrode surface. This homogeneous reaction can increase the reliability and reproducibility of the 


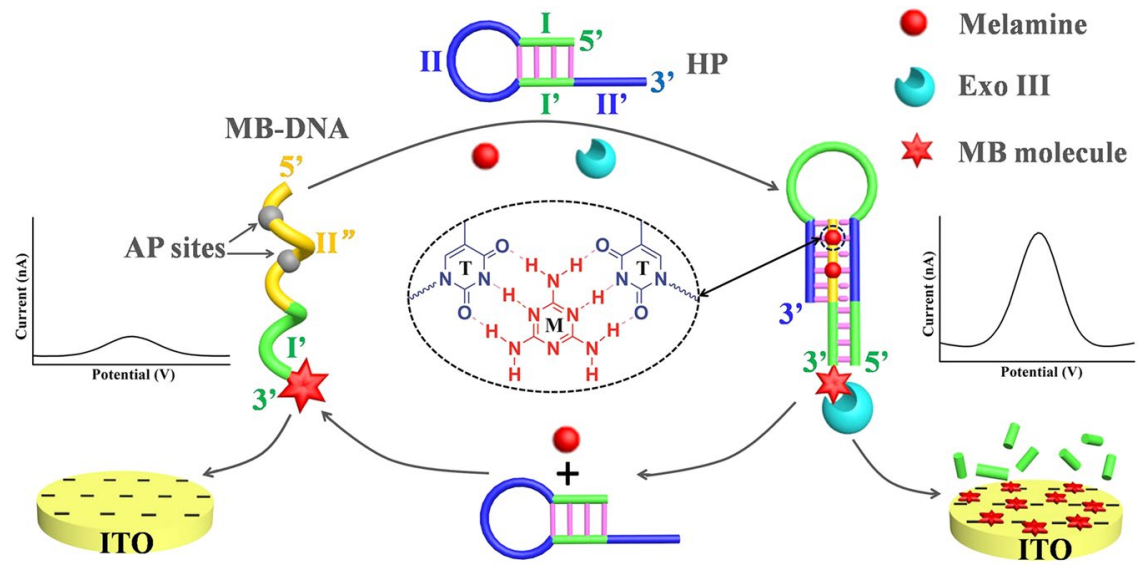

Figure 1. Principle of the homogeneous electroanalytical strategy for melamine assay.

electrochemical biosensor owing to the decreased steric hindrance effect on electrode surface. Furthermore, compared with traditional heterogeneous electrochemical strategies, the homogeneous electroanalytical methods avoid the time-consuming and tedious steps for the modification of electrode, which makes the experimental procedures more convenient and much simpler. Using these homogeneous electrochemical strategies, various targets, such as DNA, biological molecules, and metal ions, etc. have been successfully detected ${ }^{19-30}$. For example, Hsing and co-workers reported several homogeneous electroanalytical approaches for detecting $\mathrm{Hg}^{2+}$ and $\mathrm{DNA}^{22-24}$. Our group developed various homogeneous electroanalytical approaches for sensitive analysis of ATP, activities of DNA methyltransferase, alkaline phosphatase, and human telomerase $\mathrm{e}^{25-29}$.

Recently, triplex DNA has attracted much attention because of its indispensable in many biological processes, such as gene translation, gene expression, DNA transcription, and replication ${ }^{31}$. The triplex structure is constructed through binding the third DNA strand to the double-helical DNA via Hoogstern hydrogen bonds ${ }^{32-34}$. The formation of triplex structure can be regulated by external triggers such as target molecules, $\mathrm{pH}$, and metal ions $^{35-37}$, making it a potentially powerful tool for numerous applications in biological chemistry and medicine ${ }^{38,39}$. For example, triplex DNA has been utilized as recognition motifs in the design of various biosensing platforms and DNA nanomachines through the target-induced triplex DNA formation and dissociation ${ }^{40,41}$. Apart from the sequence-specific recognition of double-stranded DNA, the incorporation of the third DNA strand into the stem of molecular beacons to form hairpin-like DNA structure is an alternative strategy for the construction of biosensors $^{42-44}$. For instance, triplex molecular beacons have been utilized to design melamine aptamer by introducing an abasic (AP) site into the triplex stem ${ }^{43}$, 44 . In this aptamer, the integrated AP site could provide a hydrophobic vacancy for binding melamine through hydrogen bonding interaction between thymine and melamine. Based on this aptamer, this group has developed selective fluorescence biosensors for melamine based on $\mathrm{Mg}^{2+}$-dependent DNAzyme and silver nanoclusters, respectively ${ }^{43}, 44$. Most recently, Wang and Lin et al. have constructed a sensitive and selective electrochemical biosensor for melamine determination by designing AP site into triplex DNA, in which four DNA strands can form a T-shaped DNA nanostructure in the presence of melamine. This biosensor exhibits excellent performance for melamine detection and can be used for testing the migration of melamine from melamine bowl ${ }^{45}$.

In this work, we present a homogeneous electroanalytical strategy for sensitive assay of melamine based on the formation of triplex molecular beacon and exonuclease III (Exo III)-assisted signal molecules release. This approach employs a hairpin DNA (HP) and a 3'-methylene blue (MB) labeled DNA (MB-DNA) containing AP sites as the melamine recognition part, Exo III as a tool enzyme, and an indium tin oxide (ITO) electrode with negative charge as the working electrode. In the presence of melamine, the formation of triplex molecular beacon occurs and then MB molecules are released from MB-DNA by Exo III, resulting in a significantly increased electrochemical signal of MB. Taking advantages of the high selectivity of the DNA triplex structure containing AP sites towards melamine and the unique features of Exo III, this proposed strategy is capable of detecting melamine with high sensitivity and selectively.

\section{Results and Discussion}

Design of Melamine Detection Strategy. Figure 1 schematically illustrates the strategy for sensitive homogeneous electroanalysis of melamine, which is based on a simple system of HP, MB-DNA, and Exo III. HP is an ingeniously designed hairpin DNA, which consists of four sequential domains, namely I, II, I', and II'. The base sequence of domain I is complementary to that of domain $\mathrm{I}^{\prime}$, while domains II and $\mathrm{II}^{\prime}$ are short poly(dT) sequences. So, HP alone has a hairpin structure with a protruded fragment (domain $\mathrm{II}^{\prime}$ ). MB-DNA is a $3^{\prime}$-methylene blue (MB) labeled DNA, which contains two sequential domains: a poly(dA) sequence with two AP sites (domain $\mathrm{II}^{\prime \prime}$ ) and a same base sequence to domain $\mathrm{I}^{\prime}$. Exo III, which displays sequence dependence, can catalyze the stepwise removal of $3^{\prime}$ mononucleotides from blunt or recessed $3^{\prime}$-termini of double-stranded DNA ${ }^{46-49}$. In the absence of melamine, MB-DNA cannot reconfigure HP because of the limited stability of triplex stem with AP sites. Thus, MB-DNA maintains single strand structure and gives a very weak electrochemical signal of MB, because both negatively charged MB-DNA and ITO electrode have strong electrostatic repulsion. However, in 


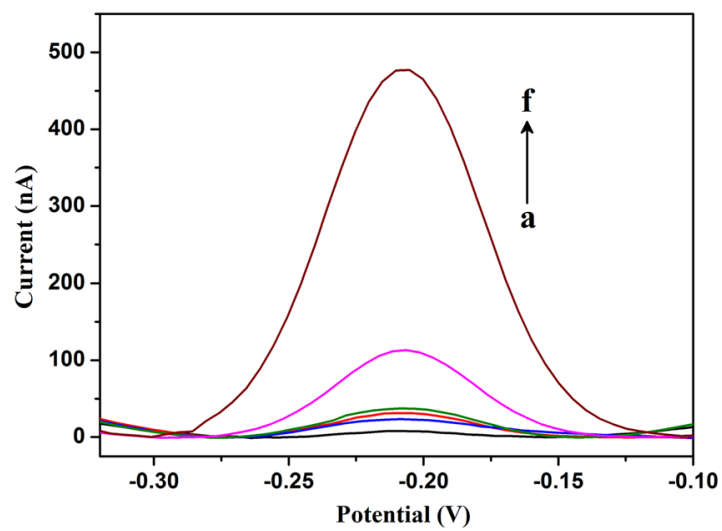

Figure 2. Differential pulse voltammograms (DPV) of the sensing system in the presence of: (a) melamine; (b) HP, MB-DNA, and melamine; (c) MB-DNA only; (d) MB-DNA and Exo III; (e) HP, MB-DNA, and Exo III; (f) HP, MB-DNA, melamine, and Exo III.

the presence of melamine, melamine can locate in the AP sites of the triplex DNA structure and form a stable T-melamine-T structure through hydrogen bonding interaction ${ }^{43}$, 44 . Thus, MB-DNA can hybridize with HP to form a molecular beacon with a triplex stem (domains II, $\mathrm{II}^{\prime}$, and $\mathrm{II}^{\prime \prime}$ ) and a protruding double strand (domains I and $I^{\prime}$ ). This duplex with blunt $3^{\prime}$ termini is then recognized and cleaved by Exo III, leading to the digestion of MB-DNA in the protruding duplex. This digestion process releases MB-labeled mononucleotide, melamine, and HP. The released melamine and HP can hybridize with another MB-DNA and trigger a new digestion process. The released MB-labeled mononucleotide, which has less negative charge than that of MB-DNA, possesses higher diffusivity toward ITO electrode owing to the reduced electrostatic repulsion. As a result, a remarkably increased electrochemical signal would be obtained. Therefore, this strategy realized the sensitive detection of melamine in a "signal-on" mode.

Feasibility Study. To verify the feasibility of melamine assay, a series of control experiments were preformed and their electrochemical responses were recorded. As shown in Fig. 2, no electrochemical signal was detected from the solution of melamine (curve a) due to the absence of electrochemical signal molecule. In the presence of HP, MB-DNA, and melamine, a negligible DPV current of MB molecule was observed (curve b), and the intensity of the current was almost the same as that obtained from MB-DNA solution (curve c), indicating that the negatively charged MB-DNA and the triplex DNA structure were hard to reach the surface of ITO electrode owing to the strong electrostatic repulsion between them. Additionally, when only Exo III was mixed with MB-DNA, the DPV current was almost unchanged (curve d), because the single strand MB-DNA can resist the digestion of Exo III. Nevertheless, because of the existence of equilibrium between different molecular conformations of HP, small portion of HP may be in a single-stranded conformation, which would hybridize with MB-DNA and produce blunt $3^{\prime}$ termini, causing the cleavage of some MB-DNA by Exo III. As a result, addition of HP and Exo III to MB-DNA solution led to a slightly increased DPV current (curve e). However, a remarkably increased DPV current of MB was obtained (curve f) when melamine was added into the reaction system, indicating the successful hybridization between HP and MB-DNA, as well as the subsequent digestion of MB-DNA by Exo III.

Optimization of Assay Conditions. In this melamine sensing strategy, the electrochemical signal was generated by the released MB-labeled mononucleotide, which originated from MB-DNA. To ensure the high sensitivity, the amounts of MB-DNA should be sufficient, thus $1 \mu \mathrm{M}$ MB-DNA was added into the reaction solution during the following experiments. Furthermore, as the formation of Hoogsteen TA.T triplex structure is sensitive to $\mathrm{pH}$ value, the influence of $\mathrm{pH}$ was optimized by analyzing the electrochemical signals in the presence of $50 \mu \mathrm{M}$ melamine. As shown in Fig. 3A, the intensity of DPV peak current obviously increased when the $\mathrm{pH}$ value increased from 6.8 to 7.2 , but further increasing the $\mathrm{pH}$ value resulted in dramatically decreased peak intensities. The highest DPV peak current was acquired at $\mathrm{pH}=7.2$, which was chosen as the optimal $\mathrm{pH}$ value. To achieve the best analytical performance, the concentration of Exo III, the reaction time of Exo III cleavage, and melamine incorporation were also optimized, respectively. Figure 3B reveals that a higher DPV signal was obtained when a higher concentration of Exo III was adopted. But the DPV peak current increased slowly when the concentration was higher than $0.75 \mathrm{U} / \mu \mathrm{L}$. Thus, $0.75 \mathrm{U} / \mu \mathrm{L}$ was selected as the optimal Exo III concentration. Figure $3 \mathrm{C}$ shows the effect of reaction time of Exo III cleavage on this melamine sensing strategy. Obviously, the DPV peak currents increased remarkably as the time of Exo III cleavage extended to $60 \mathrm{~min}$. Afterward, the DPV peak currents did not change much with increased cleavage time, suggesting that the release of MB-labeled mononucleotide from the MB-DNA was almost finished at enzymatic reaction time of $60 \mathrm{~min}$. Similarly, obviously increased DPV peak currents were observed with the extension of the melamine incorporation time and almost reach the saturation value at $5 \mathrm{~h}$ (Fig. 3D). Therefore, $60 \mathrm{~min}$ and $5 \mathrm{~h}$ were adopted as the optimal Exo III cleavage time and melamine incorporation time, respectively. 

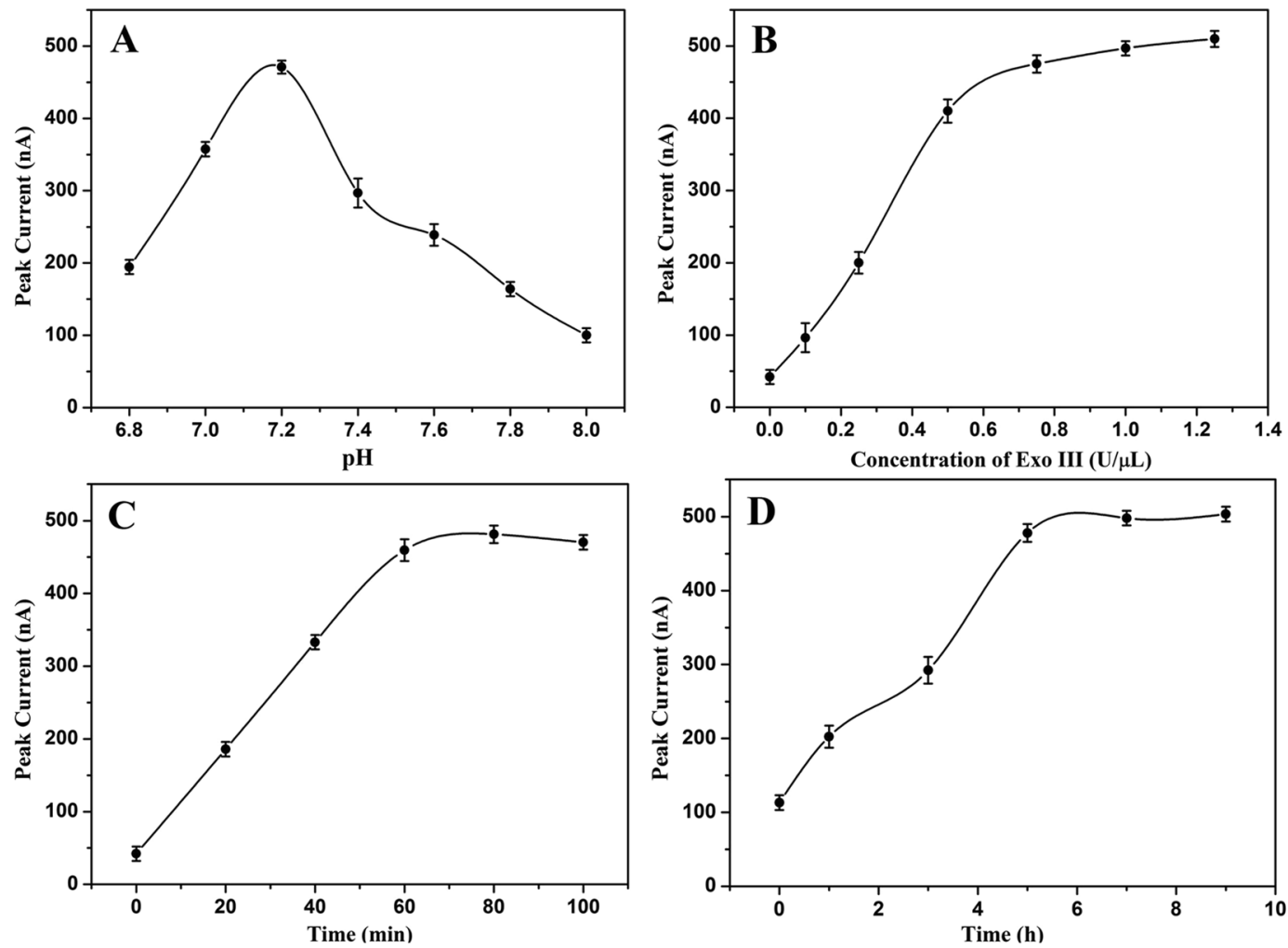

Figure 3. DPV peak current observed under (A) different $\mathrm{pH}$ values: 6.8, 7.0, 7.2, 7.4, 7.6, 7.8, and 8.0; (B) different Exo III concentrations: 0, 0.1, 0.25, 0.5, 0.75, 1, and $1.25 \mathrm{U} / \mu \mathrm{L} ;(\mathbf{C})$ different reaction time of Exo III: 0 , $20,40,60,80$, and $100 \mathrm{~min}$; (D) different reaction time of melamine: $0,1,3,5,7$, and $9 \mathrm{~h}$. The concentration of melamine was $50 \mu \mathrm{M}$. The error bars represent the standard deviation of three measurements.
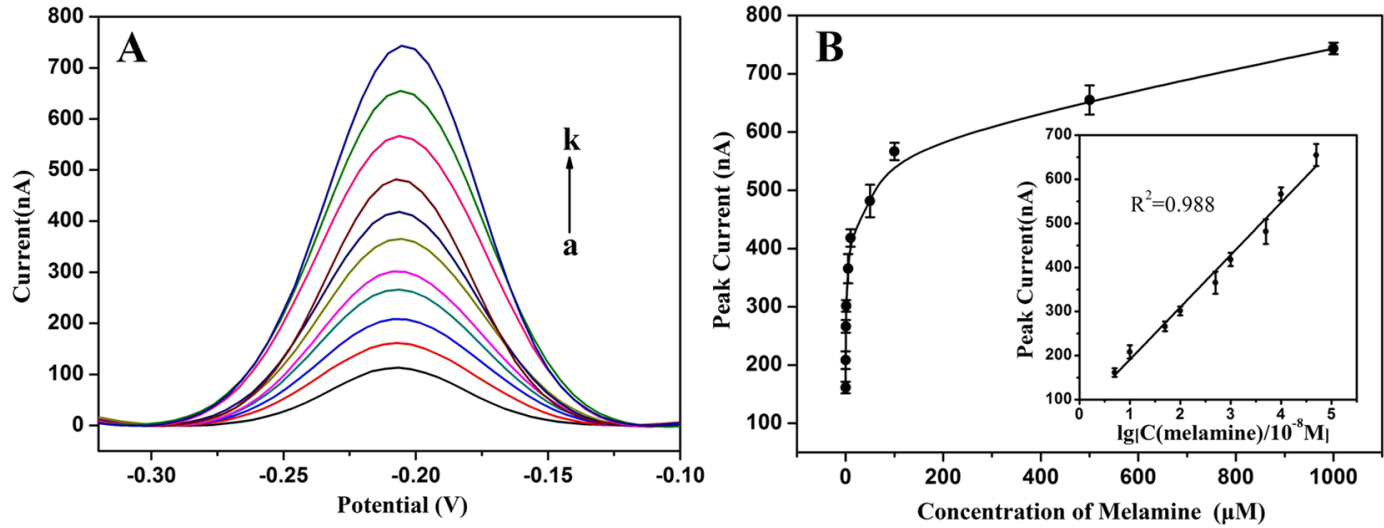

Figure 4. (A) DPV currents of the sensing system after adding melamine with different concentrations: (a-k) $0,0.05,0.1,0.5,1.0,5.0,10,50,100,500$, and $1,000 \mu \mathrm{M}$, respectively. (B) Calibration curve corresponding to the peak current versus melamine concentration ranging from $50 \mathrm{nM}$ to $1,000 \mu \mathrm{M}$. Inset: the linear relationship between DPV peak current and melamine concentration ranging from $50 \mathrm{nM}$ to $500 \mu \mathrm{M}$. The error bars represent the standard deviation of three measurements.

Sensitivity of Melamine Assay. The performance of this approach for melamine assay was investigated by analyzing the electrochemical response of the sensing system towards different concentrations of melamine. As shown in Fig. 4A, the DPV current of MB molecule was sensitive to melamine concentration and gradually increased with the increase of melamine concentration. The relationship between melamine concentration and the intensity of DPV peak current is presented in Fig. 4B. Obviously, melamine concentration ranging from 0 to $1000 \mu \mathrm{M}$ could be directly measured by this sensing strategy. Furthermore, the inset of Fig. 4B shows a good linear relationship between the intensity of peak current and the logarithm of melamine concentration ranging from $50 \mathrm{nM}$ to $500 \mu \mathrm{M}$. The correlation equation was determined to be $i_{p}=118.7 \log \mathrm{C}_{\text {melamine }}+72.0\left(\mathrm{R}^{2}=0.988\right)$, 


\begin{tabular}{|l|l|l|l|}
\hline Strategy for detection & Method & Detection limit & Ref. \\
\hline $\begin{array}{l}\text { Colorimetric assay based on uracil-5-carboxylic acid and } \\
2,4,6 \text {-trinitrobenzenesulfonic acid tailored AuNPs }\end{array}$ & Colorimetry & $5 \mathrm{ppb}$ & 51 \\
\hline Colorimetric assay based on citrate-stabilized AuNPs & Colorimetry & $25 \mathrm{ppb}$ & 52 \\
\hline Colorimetric assay based on nitroaniline-modified Ag NPs & Colorimetry & $100 \mathrm{ppb}$ & 53 \\
\hline Colorimetric detection based on cysteamine-modified AuNPs & Colorimetry & $600 \mathrm{ppb}$ & 54 \\
\hline $\begin{array}{l}\text { Fluorescence detection based on aggregation-induced emission- } \\
\text { active tetraphenylethene }\end{array}$ & Fluoremetry & $600 \mathrm{ppb}$ & 2 \\
\hline Indirect competitive ELISA method based on monoclonal antibodies & ELISA & $500 \mathrm{ppb}$ & 14 \\
\hline $\begin{array}{l}\text { Ultrasound-assisted extractive electrospray ionization mass } \\
\text { spectrometry (EESI-MS) }\end{array}$ & EESI-MS & $270 \mathrm{ppb}$ & 50 \\
\hline Ag nanorod SERS substrate based detection & SERS & $100 \mathrm{ppb}$ & 13 \\
\hline electrochemical sensor based on its copper complex & Electrochemistry & $250 \mathrm{ppb}$ & 55 \\
\hline Triplex DNA-based biosensing platform & Electrochemistry & $1.1 \mathrm{ppb}(8.7 \mathrm{nM})$ & This work \\
\hline
\end{tabular}

Table 1. Comparison of the analytical performance of the present method with that of previously reported methods.

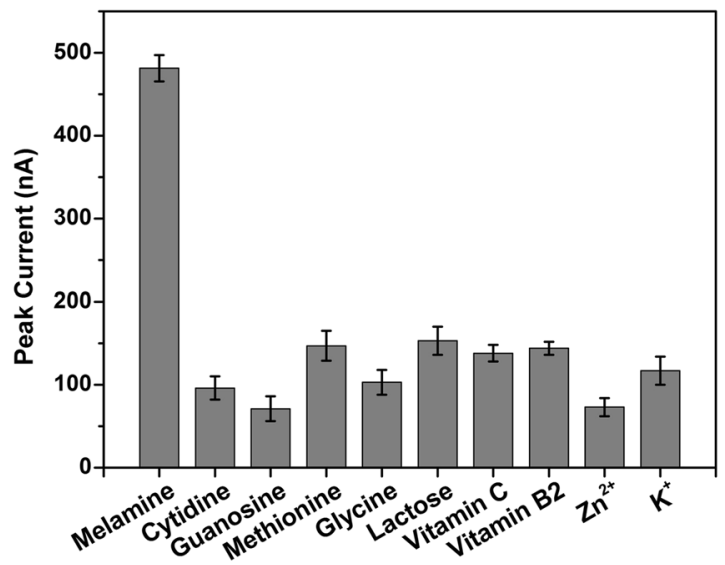

Figure 5. Comparison of DPV peak currents in the presence of melamine, cytidine, guanosine, methionine, glycine, lactose, vitamin $\mathrm{C}$, vitamin $\mathrm{B}_{2}, \mathrm{Zn}^{2+}$, and $\mathrm{K}^{+}$. The concentrations of melamine are $50 \mu \mathrm{M}$ and other substances are $100 \mu \mathrm{M}$. The error bars represent the standard deviation of three measurements.

where, $i_{p}$ is the intensity of peak current $(\mathrm{nA}), \mathrm{C}_{\text {melamine }}$ is the melamine concentration $\left(10^{-8} \mathrm{M}\right)$. The detection limit towards melamine was estimated to be $8.7 \mathrm{nM}(1.1 \mathrm{ppb})$, which is lower than that of the above mentioned biosensors (Table 1) and the maximum level permitted by China (1 ppm for infant formulas), USA and European Union (2.5 ppm), and India (1 ppm for infant formulas), respectively ${ }^{50,51}$.

Selectivity of Melamine Analysis. The selectivity of the proposed strategy for melamine assay was evaluated by testing the electrochemical response of this sensing system toward several potential interfering substances, such as cytidine, guanosine, methionine, glycine, lactose, vitamin $\mathrm{C}$, vitamin $\mathrm{B}_{2}, \mathrm{Zn}^{2+}$, and $\mathrm{K}^{+}$(Fig. 5). Compared with the significant increase of the DPV peak current upon melamine addition, there were only weak electrochemical signals observed for most other species. Therefore, this homogeneous electroanalytical strategy exhibited excellent selectivity for melamine detection and has great potential for real sample analysis application.

Real Sample Analysis. To investigate the applicability of this electroanalysis method for real sample assay, melamine in animal feed was tested by using this strategy. As melamine concentration in the animal feed was lower than the detection limit of this method, standard addition experiments were preformed. The electrochemical responses of the spiked samples were analyzed and the results are listed in Table 2. Analytical results showed that the melamine concentrations in the spiked real samples were statistically close to the concentration of melamine added and their recoveries are ranging from $90 \%$ to $97 \%$. Although these recoveries are lower than 100\%, they are still in the recovery range permitted by Chinese National Standards (60 120\%, GB/T27404-2008). Thus, random deviation of measurement is speculated to be the main reason for the inconsistency between melamine concentration detected and added. Moreover, the complex matrix such as animal feed has no evident influence on this homogeneous electroanalytical strategy, suggesting the good anti-interference capability and the potential application of this method for the analysis of melamine in real samples. 


\begin{tabular}{|l|l|l|l|l|}
\hline $\begin{array}{l}\text { Sample } \\
\text { number }\end{array}$ & $\begin{array}{l}\text { Melamine } \\
\text { added }(\boldsymbol{\mu M})\end{array}$ & $\begin{array}{l}\text { Melamine } \\
\text { detected }(\boldsymbol{\mu M})\end{array}$ & $\begin{array}{l}\text { Recovery } \\
(\%)\end{array}$ & $\begin{array}{l}\text { RSD } \\
(\%)\end{array}$ \\
\hline 1 & 5 & 4.5 & 90 & 5.7 \\
\hline 2 & 10 & 9.7 & 97 & 4.5 \\
\hline 3 & 50 & 46.0 & 92 & 7.2 \\
\hline
\end{tabular}

Table 2. Recovery data for feed samples added with different concentrations of melamine $(n=5)$.

\section{Conclusions}

In summary, a homogeneous electroanalysis platform for sensitive melamine assay was developed based on melamine-triggered formation of triplex molecular beacon and Exo III-assisted signal amplification. Taking advantage of the high binding affinity of AP site-containing triplex structure towards melamine and the unique properties of Exo III, numerous MB-labeled mononucleotides were released, which results in significantly increased electrochemical signals. All results consistently confirmed that the new electrochemical platform was applicable for melamine detection with high sensitivity and selectively. Additionally, this strategy exhibits good potential for the analysis of melamine in real samples. Thus, this strategy broadens the application of triplex DNA and presents a new strategy for the sensitive and selective detection of melamine.

\section{Methods}

Reagents. Hydrochloric acid ( $\mathrm{HCl}$ ), tris(hydroxymethyl) aminomethane (Tris), $\mathrm{MgCl}_{2}, \mathrm{NaCl}, \mathrm{ZnCl}_{2}$, ascorbic acid were obtained from Sinopharm Chemical Reagent Co., Ltd. (Shanghai, China). Exo III, guanosine monophosphate, cytidine monophosphate, glycine, and lactose were obtained from Shanghai Sangon Biotechnology Co., Ltd. (Shanghai, China). Melamine was purchased from Aladdin Reagents Co., Ltd. (Shanghai, China). All these chemicals were used without further treatment. All solutions were prepared by using ultrapure water (resistivity $18.2 \mathrm{M} \Omega \mathrm{cm}$ ) obtained from a Milli-Q water purification system (Millipore Corp., Bedford, MA, USA). The HPLC-purified DNA probes were obtained from Shanghai Sangon Biotechnology Co., Ltd. (Shanghai, China) and their sequences were listed as follows:

\section{HP: 5'-GTC TGT TTT TTT TCT CAG ACT CTT TTT TTT-3' \\ MB-DNA: 5'-AGA AA X AA X ACA GAC-MB-3' \\ $\mathrm{X}$ denotes the AP site of spacer $\mathrm{C} 3$.}

The MB-DNA and $\mathrm{HP}$ were directly used and diluted in $50 \mathrm{mM}$ Tris- $\mathrm{HCl}(\mathrm{pH}=7.2$, containing $100 \mathrm{mM} \mathrm{NaCl}$, $5 \mathrm{mM} \mathrm{MgCl}_{2}$ ) to give the stock solution of $10 \mu \mathrm{M}$.

Melamine Assay. The melamine assay was performed in $50 \mu \mathrm{L}$ Tris- $\mathrm{HCl}$ reaction buffer containing $1 \mu \mathrm{M} \mathrm{HP}$, $1 \mu \mathrm{M}$ MB-DNA, and target melamine with different concentrations. This reaction solution was incubated at $25^{\circ} \mathrm{C}$ for $5 \mathrm{~h}$, followed by the addition of $37.5 \mathrm{U}$ Exo III and incubation at $37^{\circ} \mathrm{C}$ for $60 \mathrm{~min}$ before the electrochemical measurements.

Sensing Melamine in Pig Feed. Pig feed, a mixed powder mainly consists of corn, soybean, bran, fish meal, minerals (such as $\mathrm{ZnSO}_{4}, \mathrm{KI}, \mathrm{FeSO}_{4}, \mathrm{CuSO}_{4}$ ), and vitamins (such as vitamin $\mathrm{A} / \mathrm{B}_{2} / \mathrm{C} / \mathrm{D} / \mathrm{E} / \mathrm{K}$ ), was chosen as the real sample matrix to evaluate the practical application of the as-proposed approach for melamine detection. Firstly, $1.0 \mathrm{~g}$ pig feed was mixed with $20 \mathrm{~mL}$ Tris- $\mathrm{HCl}$ reaction buffer in a centrifuge tube, and the mixture was ultrasonicated and shaken for $10 \mathrm{~min}$, respectively. After repeating this process for two times, the mixture was centrifugated at $15,000 \mathrm{rpm}$ for $10 \mathrm{~min}$, then the supernatant was collected and further filtered with $0.45 \mu \mathrm{m}$ filter before melamine assay. Finally, different concentrations of melamine were added into the feed samples to prepare the melamine spiked samples. Each concentration was repeated for 5 times, and the result was an average of 5 measurements.

Electrochemical Measurement. Differential pulse voltammetric (DPV) measurements were carried out on an Autolab Electrochemical Workstation (Metrohm, Switzerland) with a conventional three-electrode system: an ITO electrode as the working electrode, a platinum wire as the counter electrode, and an $\mathrm{Ag} / \mathrm{AgCl}$ electrode as the reference electrode. It should be noted that ITO electrode with negative charge was obtained by using a previously reported pretreatment $\operatorname{method}^{29}$.

\section{References}

1. Fodey, T. L. et al. Development of an optical biosensor based immunoassay to screen infant formula milk samples for adulteration with melamine. Anal. Chem. 83, 5012-5016 (2011).

2. Sanji, T. et al. Fluorescence "turn-on" detection of melamine with aggregation-induced-emission-active tetraphenylethe. Chem. Eur. J 18, 15254-15257 (2012).

3. Reimschuessel, R. \& Puschner, B. Melamine toxicity-stones vs. crystals. J. Medical Toxicology 6, 468-469 (2010).

4. Tang, H. W. et al. Analysis of melamine cyanurate in urine using matrix-assisted laser desorption/ionization mass spectrometry. Anal. Chem. 81, 3676-3682 (2009).

5. Miao, H. et al. Simultaneous determination of melamine, ammelide, ammeline, and cyanuric acid in milk and milk products by gas chromatography-tandem mass spectrometry. Biomed. Environ. Sci. 22, 87-94 (2009).

6. Ehling, S., Tefera, S. \& Ho, I. P. High-performance liquid chromatographic method for the simultaneous detection of the adulteration of cereal flours with melamine and related triazine by-products ammeline, ammelide, and cyanuric acid. Food Addit. Contam. 24, 1319-1325 (2007). 
7. Ai, K. L., Liu, Y. L. \& Lu, L. H. Hydrogen-bonding recognition-induced color change of gold nanoparticles for visual detection of melamine in raw milk and infant formula. J. Am. Chem. Soc. 131, 9496-9497 (2009).

8. Xin, J. Y. et al. Colorimetric detection of melamine based on methanobactin-mediated synthesis of gold nanoparticles. Food Chem. 174, 473-479 (2015).

9. Kaleeswaran, P., Nandhini, T. \& Pitchumani, K. Naked eye sensing of melamine: aggregation induced recognition by sodium D-gluconate stabilized silver nanoparticles. New J. Chem. 40, 3869-3874 (2016).

10. Ren, H., Li, M. Z., Fu, Y. Y. \& Jin, L. Silver nanoclusters functionalized by chromotropic acid and layered double hydroxides for the turn-on detection of melamine. J. Mater. Chem. C 4, 6104-6109 (2016).

11. Niu, C. X., Liu, Q. L., Shang, Z. H., Zhao, L. \& Ouyang, J. Dual-emission fluorescent sensor based on AIE organic nanoparticles and Au nanoclusters for the detection of mercury and melamine. Nanoscale 7, 8457-8465 (2015).

12. Xu, S. F. \& Lu, H. Z. One-pot synthesis of mesoporous structured ratiometric fluorescence molecularly imprinted sensor for highly sensitive detection of melamine from milk samples. Biosens. Bioelectron 73, 160-166 (2015).

13. Du, X. B., Chu, H. Y., Huang, Y. W. \& Zhao, Y. P. Qualitative and quantitative determination of melamine by surface-enhanced Raman spectroscopy using silver nanorod array substrates. Appl. Spectrosc. 64, 781-785 (2010).

14. Yin, W. W. et al. Preparation of monoclonal antibody for melamine and development of an indirect competitive ELISA for melamine detection in raw milk, milk powder, and animal feeds. J. Agric. Food Chem. 58, 8152-8157 (2010).

15. Cao, Q., Zhao, H., He, Y. J., Ding, N. \& Wang, J. Electrochemical sensing of melamine with 3,4-dihydroxyphenylacetic acid as recognition element. Anal. Chim. Acta 675, 24-28 (2010)

16. Jiang, B. Y., Yu, L., Li, F. Z. \& Xie, J. Q. A dual functional electrochemical "on-off" switch sensor for the detection of mercury(II) and melamine. Sensors and Actuators B: Chem 212, 446-450 (2015).

17. Liu, X. J. et al. A novel electrochemical biosensor for label-free detection of uracil DNA glycosylase activity based on enzymecatalyzed removal of uracil bases inducing strand release. Electrochim. Acta 113, 514-518 (2013).

18. Yin, B. C., Wu, D. \& Ye, B. C. Sensitive DNA-based electrochemical strategy for trace bleomycin detection. Anal. Chem. 82, 8272-8277 (2010).

19. Liu, S. F. et al. Exonuclease III-aided autocatalytic DNA biosensing platform for immobilization-free and ultrasensitive electrochemical detection of nucleic acid and protein. Anal. Chem. 86, 4008-4015 (2014).

20. Zhang, F. T. et al. Methylene blue as a G-quadruplex binding probe for label-free homogeneous electrochemical biosensing. Anal. Chem. 86, 9489-9495 (2014).

21. Wei, X. F. et al. DNA methylation detection and inhibitor screening based on the discrimination of the aggregation of long and short DNA on a negatively charged indium tin oxide microelectrode. Anal. Chem. 86, 3563-3567 (2014).

22. Xuan, F., Luo, X. T. \& Hsing, I. M. Ultrasensitive solution-phase electrochemical molecular beacon-based DNA detection with signal amplification by exonuclease III-assisted target recycling. Anal. Chem. 84, 5216-5220 (2012).

23. Xuan, F., Luo, X. T. \& Hsing, I. M. Conformation-dependent exonuclease III activity mediated by metal ions reshuffling on thyminerich DNA duplexes for an ultrasensitive electrochemical method for $\mathrm{Hg}^{2+}$ detection. Anal. Chem. 85, 4586-4593 (2013).

24. Xuan, F., Fan, T. W. \& Hsing, I. M. Electrochemical interrogation of kinetically-controlled dendritic DNA/PNA assembly for immobilization-free and enzyme-free nucleic acids sensing. ACS Nano 9, 5027-5033 (2015).

25. Liu, S. F., Wang, Y., Zhang, C. X., Lin, Y. \& Li, F. Homogeneous electrochemical aptamer-based ATP assay with signal amplification by exonuclease III assisted target recycling. Chem. Commun. 49, 2335-2337 (2013).

26. Li, W., Liu, X. J., Hou, T., Li, H. Y. \& Li, F. Ultrasensitive homogeneous electrochemical strategy for DNA methyltransferase activity assay based on autonomous exonuclease III-assisted isothermal cycling signal amplification. Biosens. Bioelectron 70, 304-309 (2015).

27. Wang, X. Z., Liu, X. L., Hou, T., Li, W. \& Li, F. Highly sensitive homogeneous electrochemical assay for methyltransferase activity based on methylation-responsive exonuclease III-assisted signal amplification. Sens. Actuators B: Chem 208, 575-580 (2015).

28. Zhang, L. F., Hou, T., Li, H. Y. \& Li, F. A highly sensitive homogeneous electrochemical assay for alkaline phosphatase activity based on single molecular beacon-initiated T7 exonuclease mediated signal amplification. Analyst 140, 4030-4036 (2015).

29. Liu, X. J. et al. Homogeneous electrochemical strategy for human telomerase activity assay at single-cell level based on T7 exonuclease-aided target recycling amplification. Anal. Chem. 87, 4030-4036 (2015).

30. Yu, P. et al. A label-free and cascaded dual-signaling amplified electrochemical aptasensing platform for sensitive prion assay. Biosens. Bioelectron 85, 471-478 (2016).

31. Vasquez, K. M., Narayanan, L. \& Glazer, P. M. Specific mutations induced by triplex-forming oligonucleotides in mice. Science 290, 530-533 (2000)

32. Idili, A. et al. Folding-upon-binding and signal-on electrochemical DNA sensor with high affinity and specificity. Anal. Chem. 86, 9013-9019 (2014)

33. Duca, M., Vekhoff, P., Oussedik, K., Halby, L. \& Arimondo, P. B. The triple helix: 50 years later, the outcome. Nucleic Acids Res 36, 5123-5138 (2008).

34. Chen, Z. B. et al. A novel fluorescent reagent for recognition of triplex DNA with high specificity and selectivity. Analyst 140, 7742-7747 (2015).

35. Best, G. C. \& Dervan, P. B. Energetics of formation of sixteen triple helical complexes which vary at a single position within a pyrimidine motif. J. Am. Chem. Soc. 117, 1187-1193 (1995).

36. Idili, A., Vallée-Bélisle, A. \& Ricci, F. Programmable pH-triggered DNA nanoswitches. J. Am. Chem. Soc. 136, 5836-5839 (2014).

37. Liu, Z. Y. \& Mao, C. D. Reporting transient molecular events by DNA strand displacement. Chem. Commun. 50, 8239-8241 (2014).

38. Belotserkovskii, B. P. et al. Transcription, chromatin, and epigenetics. J. Biol. Chem. 282, 32433-32441 (2007).

39. Ren, J. T. et al. pH-responsive and switchable triplex-based DNA hydrogels. Chem. Sci 6, 4190-4195 (2015).

40. Zheng, J. et al. Fabricating a reversible and regenerable Raman-active substrate with a biomolecule-controlled DNA nanomachine. J. Am. Chem. Soc. 134, 19957-19960 (2012).

41. Zhu, D. S., Zhu, J., Zhu, Y., Wang, L. \& Jiang, W. Sensitive detection of transcription factors using an $\mathrm{Ag}^{+}$-stabilized self-assembly triplex DNA molecular switch. Chem. Commun. 50, 14987-14990 (2014).

42. Xiao, Z. Y., Zhu, H. Y., Xin, A. P., Li, Y. B. \& Ling, L. S. Triplex DNA logic gate based upon switching on/off their structure by $\mathrm{Ag}^{+} /$ cysteine. Analyst 140, 7322-7326 (2015).

43. Wang, Y. et al. Activation of $\mathrm{Mg}^{2+}$-dependent DNAzymes based on AP site-containing triplex for specific melamine recognition. Analyst 140, 7508-7512 (2015)

44. Wang, Y. et al. Triplex molecular beacons for sensitive recognition of melamine based on abasic-site containing DNA and fluorescent silver nanoclusters. Chem. Commun. 51, 7958-7961 (2015).

45. Fu, C. L. et al. Homogeneous electrochemical biosensor for melamine based on DNA triplex structure and exonuclease III-assisted recycling amplification. Anal. Chem. 88, 10176-10182 (2016).

46. Ju, E. G. et al. Exonuclease-aided amplification for label-free and fluorescence turn-on DNA detection based on aggregation-induced quenching. Chem. Commun. 48, 11662-11664 (2012).

47. Zuo, X., Xia, F., Xiao, Y. \& Plaxco, K. W. Sensitive and selective amplified fluorescence DNA detection based on exonuclease IIIaided target recycling. J. Am. Chem. Soc. 132, 1816-1818 (2010).

48. Zhao, C., Wu, L., Ren, J. S. \& Qu, X. G. A label-free fluorescent turn-on enzymatic amplification assay for DNA detection using ligand-responsive G-quadruplex formation. Chem. Commun. 47, 5461-5463 (2011). 
49. Liu, X., Aizen, R., Freeman, R., Yehezkeli, O. \& Willner, I. Multiplexed aptasensors and amplified DNA sensors using functionalized graphene oxide: application for logic gate operations. ACS Nano 6, 3553-3563 (2012).

50. Zhu, L., Gamez, G., Chen, H. W., Chingin, K. \& Zenobi, R. Rapid detection of melamine in untreated milk and wheat gluten by ultrasound-assisted extractive electrospray ionization mass spectrometry (EESI-MS). Chem. Commun. 5, 559-561 (2009).

51. Bera, R. K. \& Raj, C. R. Naked eye sensing of melamine using rationally tailored gold nanoparticles: hydrogen-bonding and chargetransfer recognition. Analyst 136, 1644-1648 (2011).

52. Chi, H., Liu, B., Guan, G., Zhang, Z. \& Han, M. Y. A simple, reliable and sensitive colorimetric visualization of melamine in milk by unmodified gold nanoparticles. Analyst 135, 1070-1075 (2010).

53. Han, C. P. \& Li, H. B. Visual detection of melamine in infant formula at $0.1 \mathrm{ppm}$ level based on silver nanoparticles. Analyst 135, 583-588 (2010).

54. Liang, X. et al. Colorimetric detection of melamine in complex matrices based on cysteamine-modified gold nanoparticles. Analyst 136, 179-183 (2011).

55. Zhu, H., Zhang, S., Li, M., Shao, Y. \& Zhu, Z. Electrochemical sensor for melamine based on its copper complex. Chem Commun. 46, 2259-2261 (2010).

\section{Acknowledgements}

This work was financially supported by the National Natural Science Foundation of China (Nos 21405089, 21375072, and 21575074), the Open Funds of the State Key Laboratory of Electroanalytical Chemistry (SKLEAC201710), the Scientific Research Award Fund for Excellent Middle-Aged and Young Scientists of Shandong Province (No. BS2014CL004), the Research Foundation for Distinguished Scholars of Qingdao Agricultural University (No. 663-1114304), and the Special Foundation for Taishan Scholar of Shandong Provence (No. ts201511052).

\section{Author Contributions}

L.X. and S.M. carried out the experiments, analyzed the data, and wrote the manuscript. L.F. supervised and finalized the project. All authors reviewed and contributed to the final manuscript.

\section{Additional Information}

Competing Interests: The authors declare that they have no competing interests.

Publisher's note: Springer Nature remains neutral with regard to jurisdictional claims in published maps and institutional affiliations.

(c) (i) Open Access This article is licensed under a Creative Commons Attribution 4.0 International License, which permits use, sharing, adaptation, distribution and reproduction in any medium or format, as long as you give appropriate credit to the original author(s) and the source, provide a link to the Creative Commons license, and indicate if changes were made. The images or other third party material in this article are included in the article's Creative Commons license, unless indicated otherwise in a credit line to the material. If material is not included in the article's Creative Commons license and your intended use is not permitted by statutory regulation or exceeds the permitted use, you will need to obtain permission directly from the copyright holder. To view a copy of this license, visit http://creativecommons.org/licenses/by/4.0/.

(c) The Author(s) 2017 